\title{
Development and Validation of an Infection Risk Model for Bacterial Canker of Kiwifruit, Using a Multiplication and Dispersal Concept for Forecasting Bacterial Diseases
}

\author{
R. M. Beresford, J. L. Tyson, and W. R. Henshall
}

The New Zealand Institute for Plant \& Food Research Ltd, Mt Albert Research Centre, Private Bag 92169, Auckland 1142, New Zealand. Accepted for publication 7 October 2016.

\begin{abstract}
A weather-based disease prediction model for bacterial canker of kiwifruit (known worldwide as Psa; Pseudomonas syringae pv. actinidiae biovar 3) was developed using a new mechanistic scheme for bacterial disease forecasters, the multiplication and dispersal concept. Bacterial multiplication is estimated from a temperature function, the $M$ index, accumulated from hourly air temperature over 3 days for hours when the leaf canopy is wet. Rainfall provides free water to move inoculum to infection sites, and the daily risk indicator, the $R$ index, is the 3-day accumulation of the $M$ index output on days with total rainfall $>1 \mathrm{~mm}$; otherwise, $R$ is zero. The model was field-tested using potted kiwifruit trap plants exposed for discrete periods in infected kiwifruit orchards to identify when leaf infection occurred. In a 9-week study during spring, the $R$ index predicted leaf-spot intensity with high accuracy $\left(R^{2}=93 \%\right)$ and, in an 82-week seasonal accuracy study, prediction of infection

incidence was most accurate from spring to late summer and lower during other times. To implement the risk model for the New Zealand kiwifruit industry, a modified risk index, $R$ ', used relative humidity (RH) $>81 \%$ instead of wetness, so that 2- and 6-day weather forecasts of RH could be used. Risk index values were affected by the shape of the temperature function and an alternative 'low temperature' function for the $M$ index was identified that could be used in climates in which high temperatures are known to limit Psa development during some parts of the year. This study has shown how infection risk for bacterial diseases can be conceptualized as separate processes for temperature-dependent bacterial multiplication and rain-dependent dispersal and infection. This concept has potentially wide application for bacterial disease prediction in the same way that the infection monocycle concept has had for fungal disease prediction.
\end{abstract}

Bacterial canker of kiwifruit vines, caused by Pseudomonas syringae pv. actinidiae biovar 3 (Vanneste et al. 2013), has relatively recently spread to kiwifruit-growing areas around the world, with a severe impact on kiwifruit production in all affected areas. Both the pathogen and the disease it causes are known worldwide by researchers and kiwifruit producers as Psa. This disease was first recorded in Japan in the 1980s (Takikawa et al. 1989) and, subsequently, in China (Wang et al. 1992), Korea (Koh et al. 1994), Italy (Scortichini 1994), Portugal (Balestra et al. 2010), Turkey (Bastas and Karakaya 2012), France (Vanneste et al. 2011), Spain (Abelleira et al. 2011), and New Zealand (Everett et al. 2011).

Psa causes leaf lesions, stem cankers, shoot dieback, and wilting but does not infect fruit directly. Gold-fleshed kiwifruit cultivars (e.g., Actinidia chinensis var. chinensis 'Hort16A') are highly susceptible and vine death often occurs, whereas green-fleshed cultivars (e.g., Actinidia deliciosa var chinensis 'Hayward') are less susceptible (Balestra et al. 2009). Plant infection is believed to occur through natural openings (stomata, hydathodes, leaves, and lenticels) and through man-made wounds (e.g., pruning and girdling cuts). Leaf tissues are susceptible to infection for the first 4 weeks from emergence, after which they become highly resistant (Tyson et al. 2015).

Soon after Psa was discovered in New Zealand, the local kiwifruit industry recognized a potential benefit from a weather-based disease forecasting model for planning day-to-day orchard operations, e.g., application of protective copper sprays prior to high-risk periods and vine management operations during low-risk periods. Although it

Corresponding author: R. M. Beresford;

E-mail address: robert.beresford@ plantandfood.co.nz was believed that rainfall was required for spread of inoculum and infection (Froud et al. 2015), the exact dependence of Psa on wet weather had not been quantified. The only available models of Psa risk in relation to weather were from China, where regression equations were used to associate spring and summer leaf infection with rainfall and temperature ( $\mathrm{Li}$ et al. 2001). However, these models did not provide a basis for predicting day-to-day infection risk for disease management purposes and, therefore, an original model was required.

Many disease-forecasting models for fungal pathogens use the concept that weather conditions control key steps in the infection monocycle (e.g., spore germination and infection) and, if these conditions can be defined experimentally and then monitored in the field, infection periods can be identified, when substantial disease becomes established. Key weather parameters used for such models are wetness duration and temperature (Duthie 1997; Magarey et al. 2005) and many disease forecasters based on this concept have been developed, e.g., apple scab (MacHardy and Gadoury 1989), lettuce downy mildew (Scherm and van Bruggen 1993), strawberry gray mold (Bulger et al. 1987), and botrytis bunch rot of grapes (Ciliberti et al. 2015). Disease models for bacterial diseases have also been developed using temperature and wetness duration (or relative humidity $[\mathrm{RH}]$ ), e.g., for bacterial canker of sweet cherry caused by $P$. syringae pv. syringae (Latorre et al. 2002) and for bacterial leaf spot of tomato caused by $P$. syringae pv. tomato (Gullino et al. 2009). However, despite the strong dependence of bacterial pathogens on wet weather (Hirano and Upper 2000), the basis for forecasting bacterial diseases cannot be the same as for fungal diseases because infection mechanisms are different. Plant infection for bacteria depends on environmental conditions that allow multiplication external to host cells sufficient to induce disease symptoms (Rouse et al. 1985), and rainfall and high RH are often implicated in this process. We conceptualized a multiplication and 
dispersal concept as a general scheme for weather-based forecasters for bacterial diseases, comprising two processes: i) temperaturedependent bacterial multiplication in the presence of moisture (surface wetness or high $\mathrm{RH}$ ) to provide inoculum and ii) dispersal of bacterial inoculum to infection sites by free water (rainfall or irrigation).

The most widely deployed bacterial disease risk models are for fire blight of apple and pear, caused by Erwinia amylovora (Maryblight [Lightner and Steiner 1993], Cougarblight [Smith 1999], and Billing's integrated system [Billing 2008]). Mechanistically, these follow the concept described above. Temperature over several days preceding a day on which risk is being assessed determines the potential bacterial multiplication and, then, the occurrence of rainfall or high RH indicates suitability of conditions for infection. As for fungal disease forecasters that use the infection monocycle concept, this multiplication and dispersal concept for bacteria assumes that initial inoculum is not limiting, that disease appears after an incubation period following infection, and that epidemics develop in response to discrete weather events, rather than as a gradual polycyclic increase in disease.

This paper reports the development and testing of the Psa risk model in the Bay of Plenty Region of New Zealand, using the bacterial multiplication and dispersal concept. It includes investigation of temperature and rainfall requirements for infection, implementation of the model, evaluation of its performance under field conditions, and discussion of its transportability to other kiwifruitgrowing areas. In New Zealand, $P$. syringae pv. actinidiae is an unwanted organism and is, therefore, under government control. Laboratory-based research into the pathogen must be conducted within registered physical containment (PC) facilities and field research must be specifically authorized.

\section{MATERIALS AND METHODS}

Psa risk model description. The structure of the Psa risk model is shown in Figure 1. Bacterial multiplication over a period of 3 days is estimated, using hourly temperature as input into a temperature function called the $M$ index. Hourly $M$ values are accumulated over the current day and two preceding days (72 h) but only for hours with mean surface wetness $>50 \%$ (Fig. 1). This wetness criterion reflects an assumption that $P$. syringae pv. actinidiae multiplication is favored by moist conditions in the kiwifruit vine canopy. The infection risk on the current day is the value of the accumulated 3-day $M$ index, called the $R$ index, if the rainfall total for the previous $24 \mathrm{~h}$ is $>1 \mathrm{~mm}$; otherwise, $R$ is zero. This rainfall threshold was chosen from observations of the amount of rainfall required to wet a kiwifruit canopy sufficiently for free water to move within the canopy. For implementation of the Psa risk model, weather forecasts of RH were used and the $R$ ' index, using RH instead of wetness, was derived as a surrogate for the $R$ index and this is described in the model implementation section.

$M$ index development. The $M$ index temperature function was derived initially in 2011 from an in vitro experiment in which colony growth was measured at six temperatures. Agar plates containing King's medium B (King et al. 1954) were stab-inoculated with $P$. syringae pv. actinidiae and were incubated at constant temperatures of $5,10,15,20,25$, and $30^{\circ} \mathrm{C}$. After 3 days, colony diameter was measured, and the mean diameter of 10 colonies was expressed as the relative growth rate, i.e., the diameter at each temperature as a proportion of that at the optimum temperature.

In 2012, an in planta experiment investigated infection of kiwifruit leaves on potted plants in moist chambers at five constant temperatures in a PC-compliant facility. Ten-week-old micropropagated 'Hort16A' kiwifruit plants were spray-inoculated to runoff with $10^{9} \mathrm{CFU}$ per milliliter of an isolate of $P$. syringae pv. actinidiae biovar 3 obtained from a Bay of Plenty 'Hort16A' orchard. After inoculation, three replicate plants per treatment were placed in 360-liter, sealed plastic bins that were placed into temperature-controlled growth rooms at $5,10,15,20$, and $26^{\circ} \mathrm{C}$ for different wetting periods. A saturated atmosphere was maintained during wetting with a fine spray from a compressed air airbrush, which was controlled by a wetness sensor and data logger. Several pilot studies optimized the inoculation technique and wetting periods and confirmed that the younger, upper leaves on the plants were the most susceptible to infection. Wetness durations of $0,3,6$, 12,24 , and $48 \mathrm{~h}$ were investigated. After the wetting period, plants were removed to a constant temperature room where they were dried within $30 \mathrm{~min}$ in an airstream and were then incubated at $18^{\circ} \mathrm{C}$ and about $75 \% \mathrm{RH}$ with a 12 -h photoperiod. The majority of leaf spots appeared between 7 and 14 days after inoculation. After 21 days of incubation, the mean number of necrotic spots per leaf on the top four to five inoculated leaves was determined. Statistical analyses, including analysis of variance and regression, were performed using Minitab 16.1.1.

Field validation of the $\boldsymbol{R}$ and $\boldsymbol{R}$ ' indices. Trap plants placed in a Psa-diseased kiwifruit orchard during discrete exposure periods were used to measure the amount of infection that occurred and to determine how well the $R$ and $R$ ' indices, which were calculated using historical wetness and $\mathrm{RH}$ data, predicted infection. Potted seedlings of Actinidia chinensis var. chinensis ('Hort16A'; 12 weeks old) were exposed weekly at eight locations within a 10-year-old, diseased kiwifruit research orchard (pergola-trained 'Hort16A') in the Bay of Plenty. Six plants per location were placed on the ground beneath the vine canopy in trays that were watered regularly. After field exposure, the seedlings were incubated in a PC-compliant laboratory for 21 days at 15 to $18^{\circ} \mathrm{C}$ and 70 to $85 \% \mathrm{RH}$, after which leaf spots were counted on the top five exposed leaves on each plant. For each exposure period, six replicate plants that were not fieldexposed were maintained in the laboratory to confirm that Psa symptoms did not develop without field exposure.

Typical leaf-spot symptoms were tested for presence of $P$. syringae pv. actinidiae on five occasions. Leaf spots were excised, were

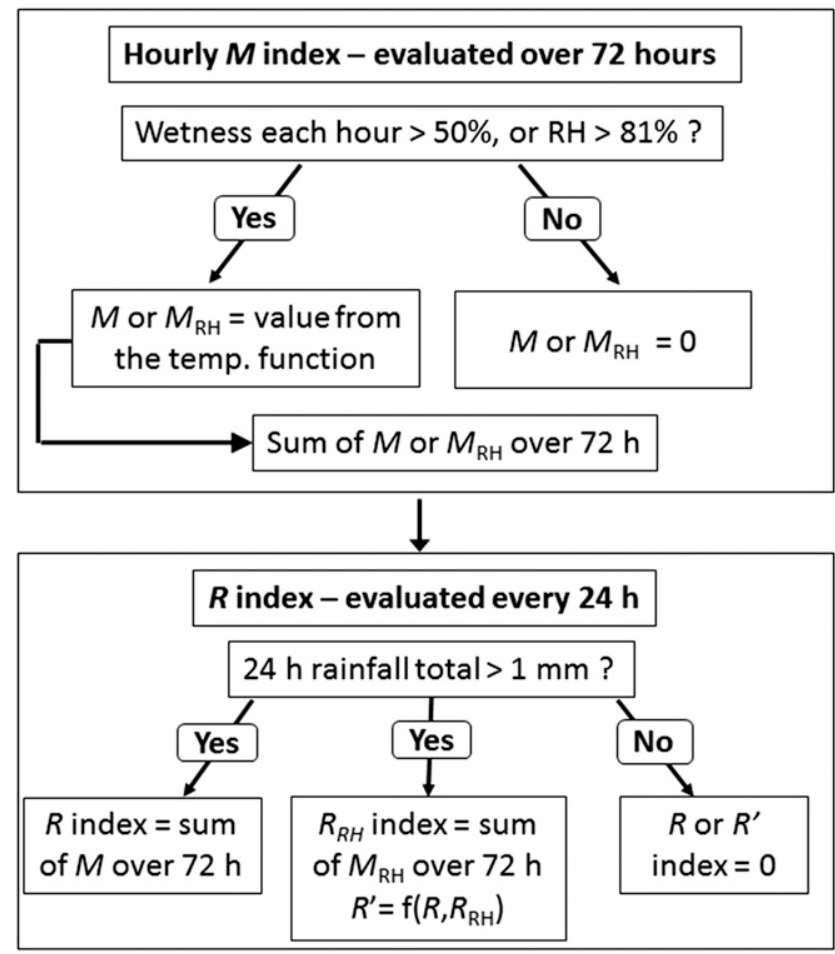

Fig. 1. The Psa risk model. Calculation of the $M$ index from hourly temperature and surface wetness data over 3 days and the $R$ index from daily rainfall data. The $M_{\mathrm{RH}}$ index and $R$ ' indexes are calculated using hourly relative humidity $(\mathrm{RH})$ and were used for implementing the model using weather forecasts. 
macerated in $200 \mu \mathrm{l}$ bacteriological saline $(0.85 \% \mathrm{NaCl}$ in sterile distilled water), and were left for $5 \mathrm{~min}$, after which $100 \mu \mathrm{l}$ of the resulting suspension was spread across a semiselective agar medium (Mohan and Schaad 1987). The agar plates were incubated at $20^{\circ} \mathrm{C}$ for $72 \mathrm{~h}$ and were then assessed for bacterial growth. DNA extraction from the mixed-colony plates and quantitative polymerase chain reaction (qPCR) conditions and analysis were done as described by Tyson et al. (2012), using the primers PsaF3 and PsaR4, developed by Rees-George et al. (2010). In addition, bacterial $23 \mathrm{~S}$ primers (Anthony et al. 2000) were used in qPCR as an internal control to check that the DNA was PCR-competent. A Cp value (crossing point or threshold value) below 30 was interpreted as a positive result, 30 to 35 as a weak positive, and a $\mathrm{Cp}$ value above 35 as a negative result.

Seasonal accuracy. The ability of the $R$ ' index to predict infection over an extended timeframe was investigated in a trap plant study similar to the field validation study. This study differed in that micropropagated 'Hort16A' plants were used, they were exposed in a diseased orchard of the less susceptible 'Hayward' cultivar and the plants were suspended about $1.2 \mathrm{~m}$ above the ground, just below the vine canopy. For 82 weeks (November 26, 2012 to July 18, 2014), 10 plants were exposed at each of four different locations in the orchard for 4 days each week (9 AM Monday to 9 AM Friday). Presence or absence of leaf-spot symptoms was recorded after 21 days of incubation and positives were only recorded if qPCR testing (as described above) indicated that $P$. syringae pv. actinidiae was present in one or more leaf lesions.

The mean value of the $R^{\prime}$ index per day was calculated for each 4-day exposure, using rainfall, temperature, and $\mathrm{RH}$ from the Te Puke Ews weather station (Table 1), which was $100 \mathrm{~m}$ from the study orchard. Each exposure period was categorized for agreement or otherwise between infection risk ( $R$ ' index) and presence or absence of Psa symptoms, using a prediction-realization analysis (Hughes et al. 2015). Exposures that were positive for infection (cases) were either true positive or false positive predictions; those that were negative for infection (noncases) were either true negative or false negative predictions. Sensitivity (proportion of cases that were true positive predictions), specificity (proportion of noncases that were true negative predictions), and proportion of correct predictions were calculated (Table 2).

Receiver operating characteristic (ROC) curve analysis examines the true positive proportion (sensitivity) and false positive proportion (1-specificity) over a range of risk indicator thresholds (Hughes 2012). This was used to determine the $R$ ' indicator value that optimized the model's ability to distinguish cases from noncases, i.e., the $R^{\prime}$ value giving the maximum difference between the true positive proportion (TPP) and the false positive proportion (FPP) (Youden 1950). The area under the ROC curve (AUC) was used to summarize overall model accuracy. Trends over time in both overall accuracy and optimum $R^{\prime}$ threshold were examined by dividing the 82 weekly exposures into 14 sets of 11 successive exposures, with the start date for each set staggered by 5 or 6 weeks.

\section{RESULTS}

$M$ index development. The optimum colony growth rate in vitro occurred at $21^{\circ} \mathrm{C}$ and a quartic polynomial fitted to the colony

TABLE 1. Weather stations used for field testing and implementing the Psa risk model

\begin{tabular}{lccc}
\hline Weather station $^{\mathrm{a}}$ & Agent no. & Latitude & Longitude \\
\hline Tauranga Aero Aws & 1615 & -37.667 & 176.620 \\
Te Puke Ews & 12428 & -37.822 & 176.324 \\
Te Puke Reeves Road Cws & 38944 & -37.859 & 176.319 \\
Katikati Apata Cws & 39268 & -37.641 & 175.973 \\
Opotiki Aero Cws & 39282 & -38.023 & 177.311 \\
\hline
\end{tabular}

a National Institute of Water and Atmosphere weather stations in the Bay of Plenty Region of New Zealand. diameter data predicted that the growth rate was zero at $-0.5^{\circ} \mathrm{C}$ and also at $31^{\circ} \mathrm{C}$ (Fig. 2A). For the in planta experiment, the optimum temperature for leaf infection was $15^{\circ} \mathrm{C}$, which was lower than the $21^{\circ} \mathrm{C}$ for in vitro growth (Fig. 2B). The response to temperature above and below the $15^{\circ} \mathrm{C}$ optimum was flatter than for the in vitro experiment, and this flat response was believed to be an artifact caused by the use of an $18^{\circ} \mathrm{C}$ incubation temperature post-wetting rather than continuing incubation at the temperature used during each wetting period. Relative infection at temperatures further from the optimum (e.g., at 5 and $25^{\circ} \mathrm{C}$ ) was believed to have been overestimated, because conditions for in planta multiplication and symptom development at $18^{\circ} \mathrm{C}$ would have been relatively more favorable than at each of the wetting temperatures. The wetness duration effect from the in planta experiment was not significant $(P=0.248)$, but mean numbers of leaf spots did show two trends: i) the zero wetness duration treatment, in which leaves dried within $0.5 \mathrm{~h}$ of inoculation, developed $31 \%$ of the maximum observed leafspot intensity, and ii) maximum leaf-spot intensity that was recorded occurred after $12 \mathrm{~h}$ of wetting (Table 3 ).

From the in vitro and in planta experiments, a temperature function for the $M$ index was chosen to represent a likely temperature response of infection risk. This was a modified quartic with similar shape to that from the in vitro experiment but with the optimum temperature at $15^{\circ} \mathrm{C}$, as suggested by the in planta temperature results (Fig. $2 \mathrm{~B}$ ):

$$
\begin{aligned}
M= & -0.000003 * T^{4}-0.00011 * T^{3}+0.00201 * T^{2} \\
& +0.0541 * T+0.247
\end{aligned}
$$

for incubation temperature $(T)$ between -6.8 and $24.8^{\circ} \mathrm{C}$.

Model implementation using $\boldsymbol{R}$ ' calculated from RH. The Psa risk model was implemented for New Zealand kiwifruit growers by the National Institute of Water and Atmosphere through a kiwifruit industry body called Kiwifruit Vine Health (KVH). Maps depicting daily infection risk were provided on the $\mathrm{KVH}$ private website, using weather forecast data. These forecasts were derived from the United Kingdom Met Office unified model and were downscaled using the New Zealand limited area model to provide 2-day (12 km spatial resolution) and 6-day ( $25 \mathrm{~km}$ spatial resolution) mesoscale forecasts.

These forecasts provided predictions of temperature, rainfall, and $\mathrm{RH}$ but not of surface wetness. Rather than attempting to model wetness from RH to calculate the $R$ index, an empirical method was employed to estimate an RH-based equivalent called the $R^{\prime}$ index. This was determined from a regression relationship between $R$ and $R_{R H}$, using historical wetness and $\mathrm{RH}$ data. The $R_{R H}$ index was an RH-based equivalent of $R$ derived from an RH-based version of the bacterial multiplication index $M_{R H}$. The $R_{R H}$ index was calculated by accumulating $M_{R H}$ values (Equation 1) over 72-h periods using hourly temperature, as described above for $M$ values. Hours were included in the 72-h $M_{R H}$ total if they were above an RH threshold. The regression relationship between $R$ and $R$ ' was derived from 17 months of hourly weather station records (August 2010 through December 2011, 487 days) at five sites in the Bay of Plenty region

TABLE 2. Structure of the prediction-realization analysis showing calculation

\begin{tabular}{|c|c|c|c|}
\hline \multirow[b]{2}{*}{ Infection predicted } & \multicolumn{2}{|c|}{ Infection observed } & \multirow[b]{2}{*}{ Totals } \\
\hline & Positive & Negative & \\
\hline Positive & $\mathrm{TP}$ & FP & Tot 3 \\
\hline Negative & FN & $\mathrm{TN}$ & Tot 4 \\
\hline \multirow[t]{3}{*}{ Totals } & Tot 1 & Tot 2 & Tot \\
\hline & Sensitivity & Specificity & Correct predictions \\
\hline & $\mathrm{TP} /$ Tot1 & $\mathrm{TN} /$ Tot 2 & $\mathrm{TP}+\mathrm{TN} / T o t$ \\
\hline
\end{tabular}
of sensitivity, specificity and correct predictions ${ }^{\mathrm{a}}$

a From the 82-week seasonal accuracy study of the Psa risk model's daily $R$, index. $\mathrm{TP}=$ true positive, $\mathrm{FP}=$ false positive, $\mathrm{FN}=$ false negative, and $\mathrm{TN}=$ true negative. 
(Table 1), providing 1,300 site-days for which $>1 \mathrm{~mm}$ of rainfall occurred. The optimum RH threshold was determined iteratively for thresholds from 75 to $90 \% \mathrm{RH}$ by regression of $R$ on $R_{R H}$ to find the highest coefficient of determination $\left(R^{2}\right)$. The optimum threshold was $81 \% \mathrm{RH}\left(R^{2}=70 \%\right)$. Because there tended to be more hours per day of $>81 \% \mathrm{RH}\left(R_{R H}\right)$ than hours per day of $>50 \%$ wetness $(R)$, the regression equation at the optimum RH was used to adjust the $R_{R H}$ values to provide $R$ ' as an unbiased estimate of $R$. The regression equation was:

$$
R^{\prime}=0.749 * R_{R H}+2.412
$$

Field validation of the $\boldsymbol{R}$ and $\boldsymbol{R}$ ' indices. Leaf-spot symptoms developed on the exposed trap plant leaves for seven of the nine weekly exposures (Table 4). The incubation period between the first rainfall event during field exposure that was likely to have produced infection and the first appearance of symptoms during postexposure incubation varied from 8 to 11 days, with a mean of 10.7 days. For weeks 1 and 8 , no symptoms developed, there was no rainfall, and the risk model $R$ and $R^{\prime}$ index values were zero.

Both the $R$ and $R$ ' indices were good predictors of leaf-spot intensity, with $R^{2}$ values $>0.9$ (Fig. $3 \mathrm{~A}$ and $\mathrm{B}$ ). The weekly rainfall total did not show a significant regression coefficient $(P=0.220)$, but the cube root of rainfall was a reasonable predictor of leaf-spot intensity, with an $R^{2}$ value of 0.74 (Fig. 3C) The lack of infection in the two weeks with zero rainfall showed that rainfall was a requirement for infection, but rainfall was not as good a predictor of the amount of infection as the $R$ and $R$ ' indices were. This indicated that the assumption about representing bacterial multiplication as an accumulation of the temperature-dependent $M$ index during wet hours was reasonable.

Seasonal accuracy. The prediction-realization analysis for the entire 82 week dataset showed that an $R^{\prime}$ index value of five gave the greatest overall sensitivity $(94.6 \%)$ and the greatest percentage of correct predictions (82.9\%), whereas, at higher thresholds (e.g., 10 and 15), sensitivity decreased markedly and, although specificity increased, the percentage of correct predictions did not improve (Table 5).

The ROC curve analysis showed that overall prediction accuracy (AUC) of the $R$ ' index varied over time (Fig. 4A). It was near-perfect from the start of the study in November 2012 (midspring) until late February 2013 (late summer) and, again, from early October 2013 (early spring) until late March 2014 (midautumn). The decline in accuracy in late summer and autumn 2013 was associated with a period of unusually infrequent rainfall (Fig. 4B). Periods when accuracy was greatest tended to be those with a lower value for the optimum $R$ ' index threshold (Fig. 4A). Fluctuations in disease intensity in the 'Hayward' kiwifruit canopy in which the trap plants were exposed may have influenced model accuracy by affecting inoculum availability; however, disease records were not made.
Model sensitivity to the rainfall threshold. The value of the Psa risk model $R^{\prime}$ index is $>0$ only for days with $>1 \mathrm{~mm}$ of rainfall. To determine whether $1 \mathrm{~mm}$ of rainfall was the best threshold for correctly classifying days with nonzero risk, a rainfall sensitivity analysis was conducted, using the 82-exposure trap plant dataset from the seasonal accuracy study. Rainfall thresholds of $0,0.5,1,2$, $4,8,15,20$, and $30 \mathrm{~mm}$ were examined for their effect on overall prediction accuracy (AUC) and on the model's ability to differentiate cases from noncases (maximum value of TPP - FPP). Overall model accuracy was highest for rainfall thresholds between 0.5 and $2 \mathrm{~mm}$ and the proportion of days correctly classified as zero or nonzero risk was greatest for rainfall thresholds of 1 or $2 \mathrm{~mm}$ (Fig. 5). Maximum TPP - FPP occurred at an $R$ ' index threshold of 5 for all rainfall thresholds except $0 \mathrm{~mm}$, for which it was 10 . These results confirmed the assumption that Psa infection responds to small amounts of rainfall and that the $1-\mathrm{mm}$ threshold chosen for the model was appropriate.

Model sensitivity to temperature function shape. The magnitude of $R^{\prime}$ for days with nonzero risk (>1 mm rainfall) is determined partly by the temperature function used to calculate the hourly $M$ or $M_{\mathrm{RH}}$ index. Two alternative temperature functions were compared with the $M$ index to determine whether shape of the function had an important influence on the calculated $R$ ' values in different seasons (Fig. 6A). Weather data from the Te Puke Ews weather station (Table 1) for one year (July 1, 2014 to June 30, 2015) were used. The in planta function was an interpretation of the response of kiwifruit leaf infection to different controlled temperatures (Fig. 2B) and had a $15^{\circ} \mathrm{C}$ optimum temperature, like the $M$ index, but a broader peak. The 'low temperature' function had a $10^{\circ} \mathrm{C}$ optimum and a narrow peak, similar to the $M$ index, and gave no risk accumulation above $20^{\circ} \mathrm{C}$.

When $R^{\prime}$ index values derived from the three temperature functions were averaged over each of four seasons, the in planta function gave higher $R^{\prime}$ values than the $M$ index, particularly in

TABLE 3. Mean leaf-spot intensity a associated with the nonsignificant main effect for wetness duration ${ }^{\mathrm{b}}$

\begin{tabular}{lcc}
\hline & \multicolumn{2}{c}{ Spots per leaf } \\
\cline { 2 - 3 } Wetness duration (h) & No. & Relative no. (\%) \\
\hline 0 & 7.0 & 31 \\
3 & 15.6 & 68 \\
6 & 11.8 & 51 \\
12 & 22.9 & 100 \\
24 & 20.0 & 87 \\
48 & 20.3 & 88 \\
$F$ prob. & $P=0.248$ & \\
\hline
\end{tabular}

a Number of Pseudomonas syringae pv. actinidiae lesions per leaf.

b Measured in the in planta experiment on inoculated 'Hort16A' kiwifruit plants.
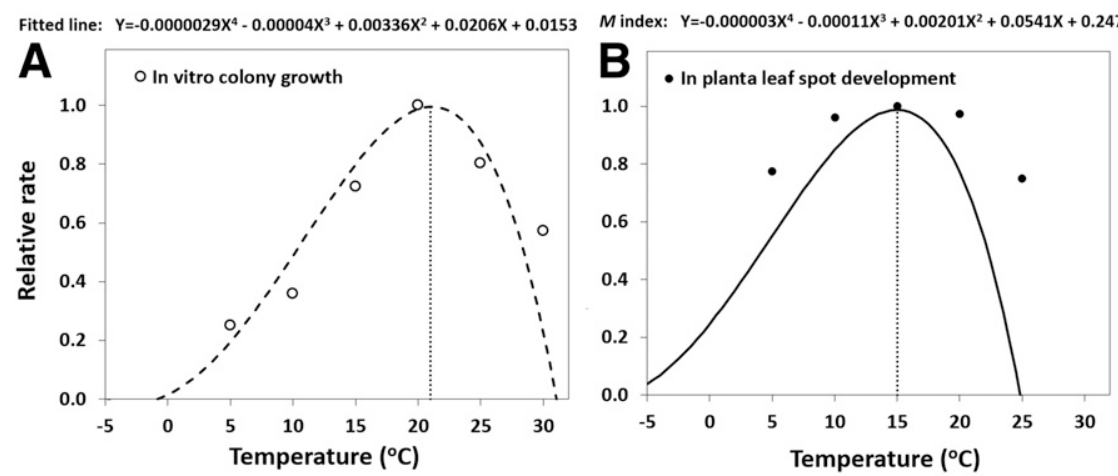

Fig. 2. A, Response of Pseudomonas syringae pv. actinidiae growth in culture to temperature (open circles and dashed line), showing an optimum temperature at $21^{\circ} \mathrm{C}$. B, Response of kiwifruit leaf infection to temperature, showing an optimum at $15^{\circ} \mathrm{C}$ (solid circles). The solid line is the Psa risk model $M$ index, which is a quartic polynomial with similar shape to the fitted line in A but adjusted to an optimum temperature of $15^{\circ} \mathrm{C}$, based on the in planta experiment. 
winter and autumn, reflecting the higher rate of index accumulation at lower temperatures (Fig. 6B). The low temp function gave higher $R$ ' values than the $M$ index in winter, similar values in spring, but much lower values in summer and autumn, due to the lower optimum temperature and $20^{\circ} \mathrm{C}$ cutoff.

\section{DISCUSSION}

Role of rainfall. The multiplication and dispersal concept underlying the Psa risk model provided a simple and practical framework for model development that was shown through field testing to provide accurate prediction of Psa infection. Within this quasi-mechanistic concept, rainfall provides free water for movement of bacteria to infection sites, although it is also involved in providing wetness and high RH that assists bacterial multiplication. Hirano and Upper (2000) emphasized a role of rainfall in stimulating multiplication, but we believe multiplication is more likely to be temperature limited under springtime conditions in temperate climates. Hirano and Upper (2000) also considered that heavy rainfall diminishes disease risk by washing inoculum out of the leaf canopy. Our rainfall sensitivity analysis was consistent with this suggestion, where prediction accuracy decreased as the rainfall threshold increased from 2 to $30 \mathrm{~mm}$ per day. There was a nonlinear response of leaf-spot intensity to rainfall amount in the field validation study, with a cube root transformation of rainfall providing a good fit. This nonlinearity is consistent with the suggestion that small amounts of rainfall (e.g., 1 to $5 \mathrm{~mm}$ ) are sufficient to promote Psa infection. The rainfall threshold of $1 \mathrm{~mm}$ per day was chosen to represent the minimum amount of rainfall required to wet a kiwifruit vine canopy sufficiently to disperse inoculum and promote infection, and our model sensitivity testing suggested this is reasonable.

Role of surface wetness and RH. We were not able to show that wetness duration had a significant effect on infection in the in planta controlled environment study. However, the inoculum suspension provided sufficient wetness to produce some infection ( $31 \%$ of maximum) with about $0.5 \mathrm{~h}$ of wetting. A similar result was reported by Zehr et al. (1996) for Xanthomonas campestris pv. pruni, in which peach leaves inoculated with $10^{7}$ cells per milliliter developed some necrosis as a result of inoculation with no further wetting, although a substantial increase in necrosis occurred with up to $48 \mathrm{~h}$ of additional wetting. For tomato plants inoculated with $10^{7}$ cells per milliliter of Pseudomonas syringae pv. tomato, $17 \%$ infection occurred with $1 \mathrm{~h}$ of incubation at $100 \% \mathrm{RH}$ and infection increased to $46 \%$ after a further $24 \mathrm{~h}$ of high RH incubation (Gullino et al. 2009). Those studies together with the present one show that bacterial infection can occur with a very short wetting period when high concentrations of cells are introduced to infection sites. Within the concept used for the Psa risk model, the role of surface wetness (or high RH as a surrogate for wetness) is in bacterial multiplication rather than infection. It is assumed that, during periods with wetness and favorable temperature, multiplication produces a high concentration of bacteria that can then be moved by rainfall to infection sites.

The RH-based $R$ ' index allowed the Psa risk model to be implemented in New Zealand using RH data from weather forecasts. The field validation trap plant study showed that the $R$ ' index had similar accuracy to the wetness-based $R$ index and this model could, therefore, be implemented in other regions, using either wetness or $\mathrm{RH}$. If RH were used, the $R^{\prime}$ correction should be locally calibrated. For implementation in other regions, it would be desirable to verify locally how the prediction accuracy varies seasonally, as was done using trap plants in both this study and in Italy (Antoniacci et al. 2015).

Role of temperature. In many regions Psa symptom development decreases during summer months, e.g., Japan (Serizawa and Ichikawa 1993), South Korea (Koh et al. 1994), China (Li et al. 2001), New Zealand (Vanneste 2013), and Italy (Antoniacci et al. 2015). In New Zealand's Bay of Plenty region, the decline in Psa symptoms from late summer coincides with both the highest daily mean temperatures $\left(17\right.$ to $\left.20^{\circ} \mathrm{C}\right)$ and the lowest rainfall frequency (Fig. 4B), so either factor could cause this decline. In the Emilia Romanga region of Italy, summer mean temperatures are hotter $\left(>25^{\circ} \mathrm{C}\right)$, and when the Psa risk model was tested there, it only

TABLE 4. Leaf-spot intensity in Actinidia chinensis var. chinensis 'Hort16A' trap plants resulting from weekly exposure periods in a diseased kiwifruit orchard ${ }^{a}$ Week of exposure (2011) $\quad$ Mean number of spots/leaf $\quad$ Weekly $R$ index total $\quad$ Weekly $R$ ' index total $\quad$ Total rainfall (mm) Incubation period (days)

1: Sept. 1-8 0

2: Sept. $8-15$

3: Sept. $15-22$

4: Sept. $22-29$

5: Sept. $29-$ Oct. 6

6: Oct. $6-13$

7: Oct. $13-20$

8: Oct. $20-27$

9: Oct. 27-Nov. 3

$\begin{array}{rr}0 & \\ 13 & 3 \\ 12 & 5 \\ 11 & 1 \\ 29 & 8 \\ 29 & 95 \\ 43 & 13 \\ 0 & 93 \\ 37 & 9\end{array}$

0
32
52
10
81
95
34
0
93

$\begin{array}{rr}0 & \\ 23 & 22.2 \\ 25 & 1 \\ 10 & \\ 75 & 45.9 \\ 90 & 16 \\ 18 & 58.3 \\ 0 & \\ 25 & 5\end{array}$

a Weekly totals for the Psa risk model's $R$ index (wetness), $R$ ' index (relative humidity) and rainfall. Incubation period refers to the interval from the first rainfall event during field exposure to the first appearance of symptoms during laboratory incubation (Mean $=10.7$ days).
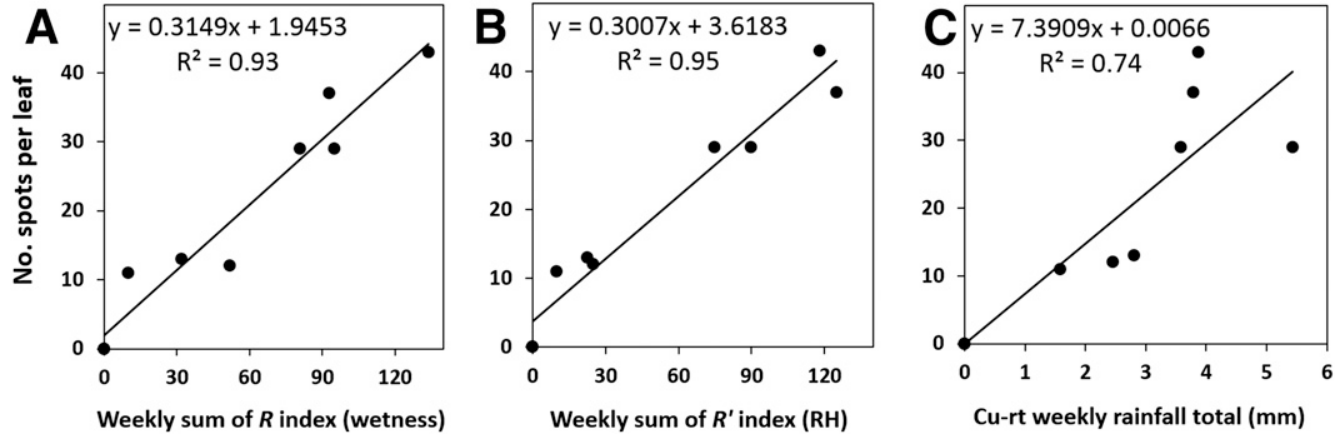

Fig. 3. Regression of leaf-spot intensity in weekly exposed kiwifruit trap plants on the $x$ variates. A, Psa risk model $R$ index using surface wetness. B, $R$ ' index using relative humidity $(\mathrm{RH})$. C, Cube root of weekly rainfall total. 
TABLE 5. Prediction-realization analysis for the Psa risk model 1 for three values of the $R$ ' index threshold ${ }^{\text {a }}$

\begin{tabular}{|c|c|c|c|}
\hline \multirow[b]{2}{*}{ Infection predicted } & \multicolumn{2}{|c|}{ Infection observed } & \multirow[b]{2}{*}{ Totals } \\
\hline & Positive & Negative & \\
\hline \multicolumn{4}{|l|}{$R^{\prime}$ threshold $=5$} \\
\hline Positive & 35 & 12 & 47 \\
\hline Negative & 2 & 33 & 35 \\
\hline \multirow[t]{3}{*}{ Totals } & 37 & 45 & 82 \\
\hline & Sensitivity (\%) & Specificity (\%) & $\begin{array}{l}\text { Correct } \\
\text { predictions (\%) }\end{array}$ \\
\hline & 95 & 73 & 83 \\
\hline \multicolumn{4}{|l|}{$R^{\prime}$ threshold $=10$} \\
\hline Positive & 26 & 3 & 29 \\
\hline Negative & 11 & 42 & 53 \\
\hline \multirow[t]{3}{*}{ Totals } & 37 & 45 & 82 \\
\hline & Sensitivity (\%) & Specificity (\%) & $\begin{array}{l}\text { Correct } \\
\text { predictions }(\%)\end{array}$ \\
\hline & 70 & 93 & 83 \\
\hline \multicolumn{4}{|l|}{$R^{\prime}$ threshold $=15$} \\
\hline Positive & 21 & 2 & 23 \\
\hline Negative & 16 & 43 & 59 \\
\hline \multirow[t]{3}{*}{ Totals } & 37 & 45 & 82 \\
\hline & Sensitivity (\%) & Specificity (\%) & $\begin{array}{l}\text { Correct } \\
\text { predictions }(\%)\end{array}$ \\
\hline & 57 & 96 & 78 \\
\hline
\end{tabular}

a Over the entire 82-week seasonal accuracy study. predicted leaf spotting on potted trap plants accurately during spring (March to the first week of June) but not during the rest of summer (Antoniacci et al. 2015). In Japan, Serizawa and Ichikawa (1993) showed that very little symptom development occurred in inoculated kiwifruit canes at mean temperatures $>20^{\circ} \mathrm{C}$, indicating that decreased symptom development can be due to high temperatures rather than infrequent rainfall. This is confirmed in southern South Korea, where the highest daily mean temperatures $\left(25\right.$ to $\left.29^{\circ} \mathrm{C}\right)$ occur during the rainy season and Psa development declines even though rainfall is not limiting at that time (Koh et al. 1994). Mean daily temperatures $>20^{\circ} \mathrm{C}$ can clearly limit disease development, either by limiting infection or by promoting host plant resistance.

The amount of Psa infection on rainy days appears to be limited by either low or high temperatures, both of which can be suboptimal for bacterial multiplication. Both these aspects must be captured in the temperature function used for the $M$ or $M_{\mathrm{RH}}$ index. In our sensitivity analyses, the broad peak and $15^{\circ} \mathrm{C}$ optimum of the in planta function gave slightly higher $R^{\prime}$ estimates in all seasons than the original $M$ index function, making it less appropriate for high summer temperatures. The low temperature function, with its optimum of $10^{\circ} \mathrm{C}$ and maximum of $20^{\circ} \mathrm{C}$, gave much lower $R^{\prime}$ values during summer and autumn, and this function may better reflect the lower infection risk in areas where Psa development is limited by high temperatures.
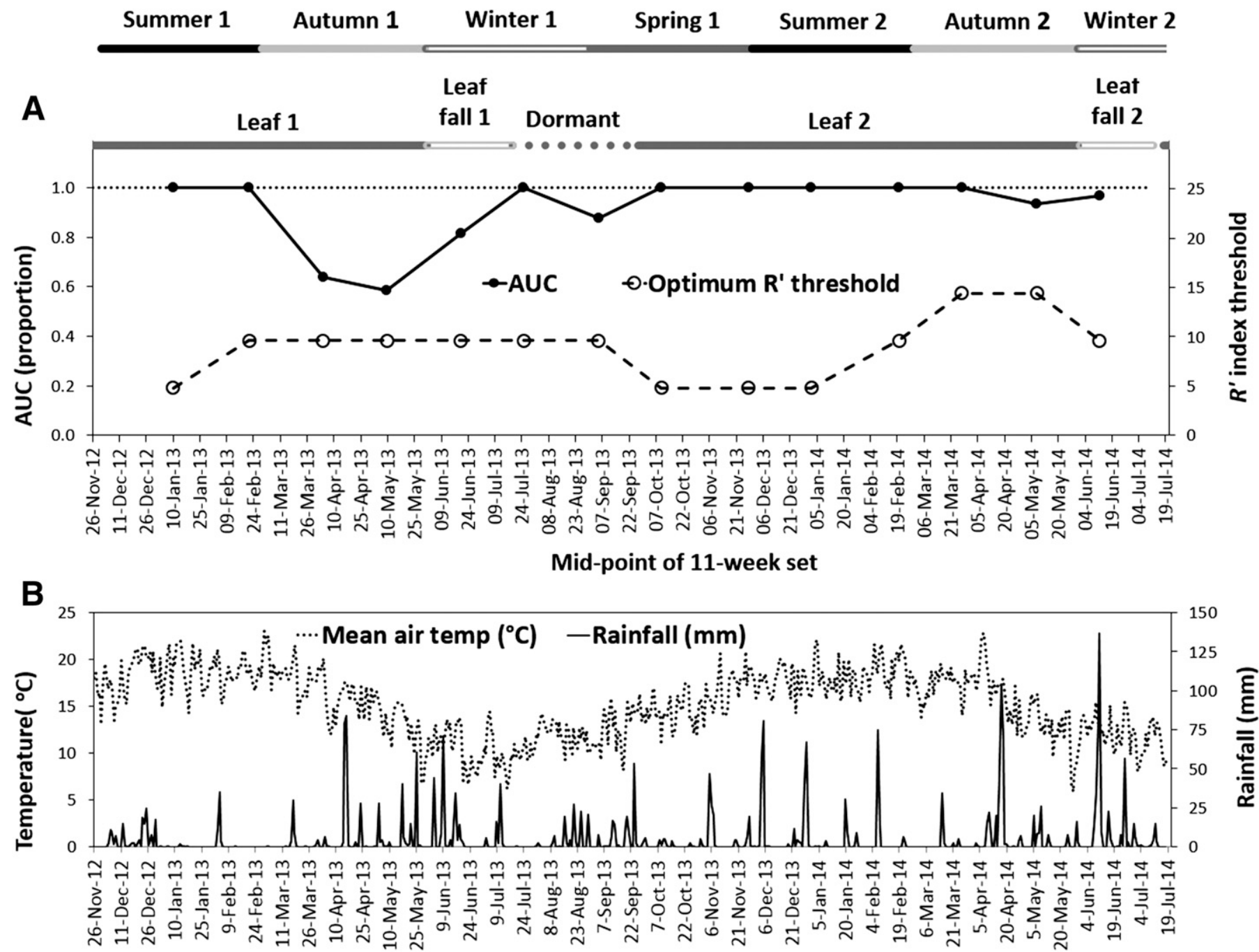

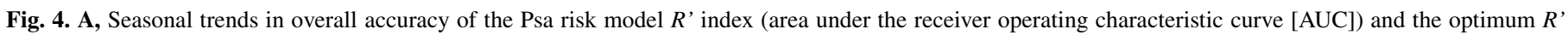

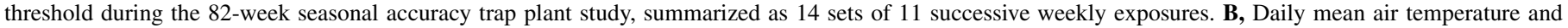
rainfall associated with the seasonal accuracy study. 
Kiwifruit plants can be damaged by frosts during autumn, winter, and spring (Pyke et al. 1986) and, as happens with other pseudomonad diseases, e.g., bacterial canker of cherry (Sobiczewski and Jones 1992), frost can exacerbate Psa development (Ferrante and Scortichini 2014). The Psa risk model does not currently address the effect of frost on disease development and further research into this aspect of this disease's temperature dependence is required.

Calibration of the $\boldsymbol{R}^{\prime}$ index. The use of any predictive model for making disease management decisions requires an understanding of how different values of the risk indicator variable relate to likely disease outcomes and their consequences (McRoberts et al. 2011). For the Psa risk model, the $R$ ' index showed a close relationship with leaf-spotting intensity on trap plants exposed weekly, indicating it was a satisfactory indicator of infection risk. The optimum $R^{\prime}$ threshold was found to be between 5 and 10 in the prediction-realization analysis of the seasonal accuracy study. At higher $R$ ' thresholds, sensitivity decreased because of an increasing false positive rate. Although specificity was worse at a threshold of 5 , because of a high false negative rate, failure to detect infection events (false positives) could incur greater economic consequences through failure to control disease than incorrectly predicted infection when it did not occur (false negatives). The ROC curve analysis showed very high accuracy from spring to late summer or early autumn but variable accuracy at some other times of year. The optimum risk model threshold was generally 5 to 10 , and this is the range of $R^{\prime}$ values that should be used for decision making on Psa management.

Representation of orchard infection by potted plants. Potted kiwifruit plants were used to calibrate the Psa risk model using natural inoculum in kiwifruit orchard canopies. The model accurately predicted leaf infection on the potted trap plants during spring and summer and it is expected that these predictions would be accurate for infection of susceptible leaves within the orchard canopy. The leaves on the exposed trap plants were of the same age year round and, therefore, the amount of susceptible tissue available for infection was constant. The susceptibility to infection of leaves within a kiwifruit canopy would, however, change seasonally

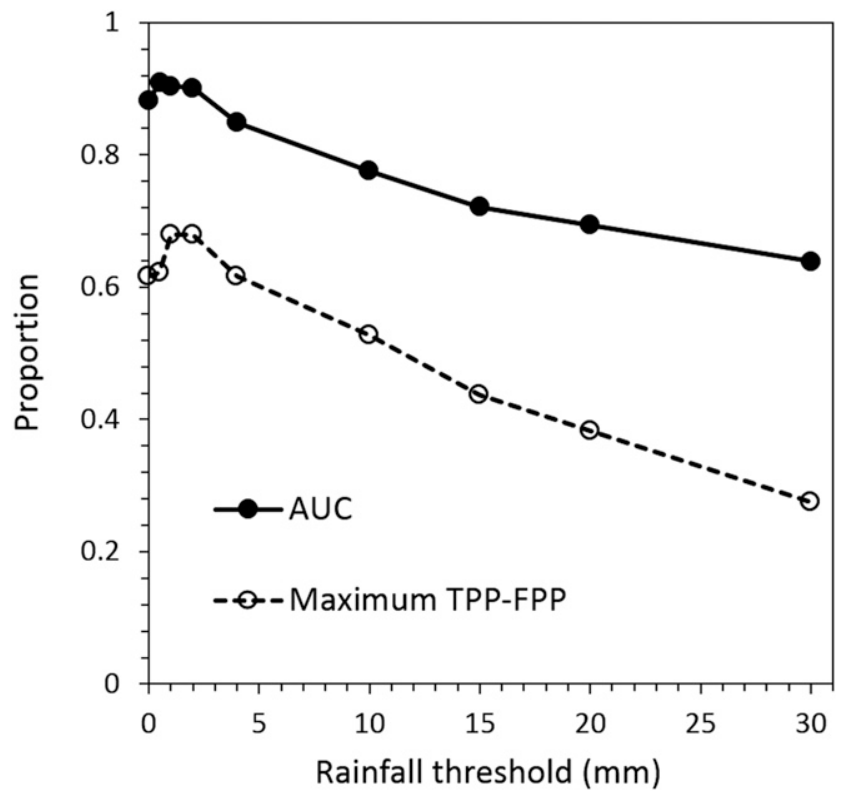

Fig. 5. Sensitivity of the Psa risk model to the rainfall threshold used to trigger output of nonzero $R$ ' index values. Accuracy of infection prediction in 82 fourday trap plant exposures was examined for nine rainfall thresholds between 0 and $30 \mathrm{~mm}$ in terms of overall accuracy, as area under the receiver operating characteristic curve (AUC), and the model's ability to differentiate between cases and noncases, as the maximum difference between the true positive proportion (TPP) and the false positive proportion (FPP). because of ontogenic resistance (Ficke et al. 2002). Kiwifruit leaves become resistant to infection about 4 weeks after emergence (Tyson et al. 2015) and this would create a strong age-related susceptibility structure within the canopy. The proportion of susceptible leaves would decrease as the total number of leaves increases in the expanding canopy. The risk model's prediction of leaf infection, therefore, would only relate to the relatively young leaves near the growing tips of shoots.

Although leaf spotting is an important indicator of new Psa infection activity during spring, it is stem infection affecting trunks and canes that is of most concern to kiwifruit growers. The Psa risk model's ability to predict stem infection was not tested in this study, although we would expect temperature, wetness, and rainfall conditions suitable for leaf infection to correlate with those suitable for stem infection. Further research is required to calibrate this relationship as well as to determine whether stem tissues also show ontogenic resistance and to quantify the relative amounts of infection arising from natural wounds (e.g., leaf scars and wind damage) versus man-made wounds (e.g., pruning, vine training, and stem girdling).

Conclusions. This study has shown that, as for fire blight of apple and pear, infection risk for kiwifruit bacterial canker can be conceptualized as separate processes for temperature-dependent bacterial multiplication and rain-dependent dispersal and infection. This concept has potentially wide application for bacterial disease prediction in the same way that the infection monocycle concept has had for fungal disease prediction. The validation of the Psa risk

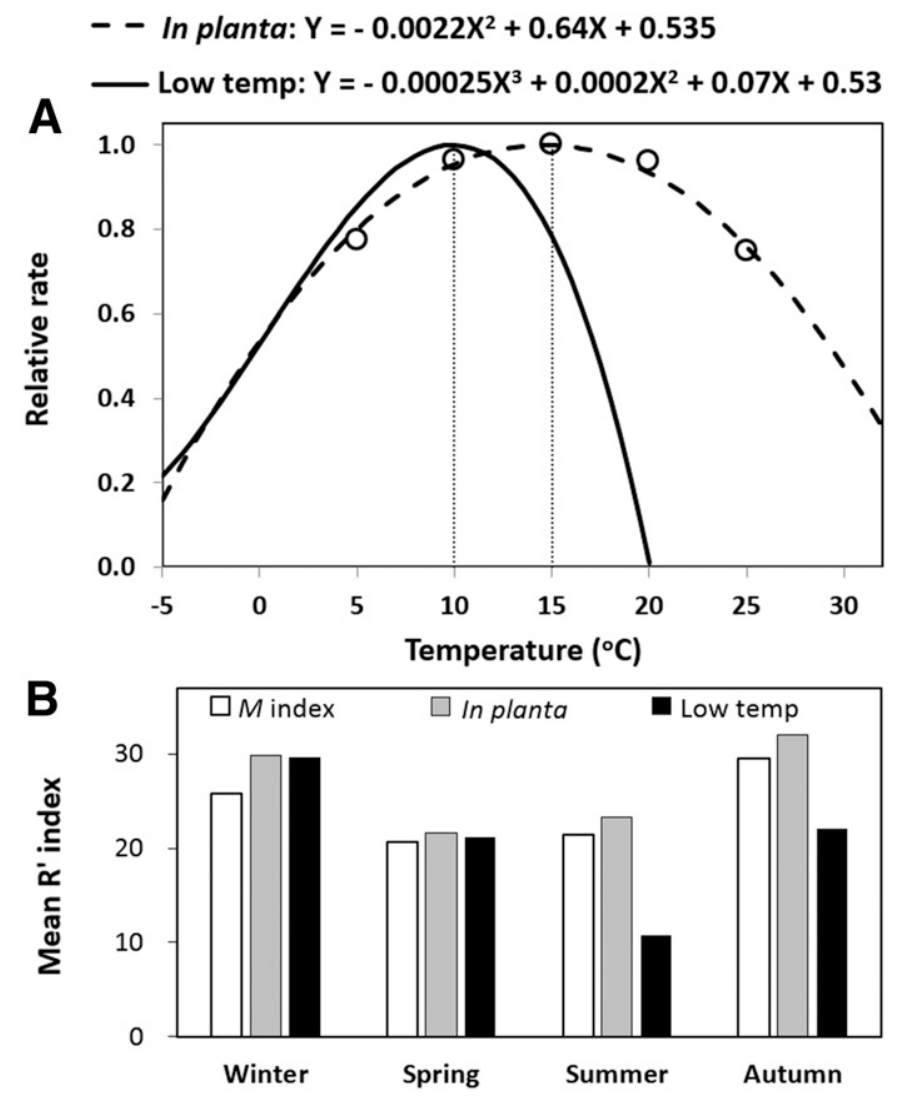

Fig. 6. A, Two alternative shapes for the temperature function that were compared with the $M$ index for their effect on $R^{\prime}$ index values. The in planta function, with a $15^{\circ} \mathrm{C}$ optimum and a relatively broad peak, was an interpretation of the response of kiwifruit leaf infection to different controlled temperatures. The low temp function, with a $10^{\circ} \mathrm{C}$ optimum and a narrow peak, similar to the $M$ index, gave no risk accumulation above $20^{\circ} \mathrm{C}$. B, Seasonal mean values of the $R^{\prime}$ index for the three temperature functions that were compared for calculating the $M_{\mathrm{RH}}$ index. Mean air temperatures during each season were: winter, $9.7^{\circ} \mathrm{C}$; spring, $14.1^{\circ} \mathrm{C}$; summer, $19.1^{\circ} \mathrm{C}$; and autumn, $15.3^{\circ} \mathrm{C}$. 
model in this study, using prediction-realization analysis and ROC curve analysis, showed that the Psa risk model has high accuracy during the important spring period of disease development. This study provides researchers and kiwifruit growers worldwide with important new information about Psa epidemiology and how the Psa risk model can be used for decision-making in the management of this troublesome disease.

\section{ACKNOWLEDGMENTS}

We thank Zespri Group Ltd. for funding the development of the Psa risk model and Kiwifruit Vine Health and the National Institute of Water and Atmosphere for their work in its implementation. Thanks are also due to A. McKay, M. Manning, N. Larsen, C. Curtis, S. Dobson, and C. McKenna for their technical expertise during this research.

\section{LITERATURE CITED}

Abelleira, A., López, M. M., Peñalver, J., Aguín, O., Mansilla, J. P., Picoaga, A., and García, M. J. 2011. First report of bacterial canker of kiwifruit caused by Pseudomonas syringae pv. actinidiae in Spain. Plant Dis. 95:1583.

Anthony, R. M., Brown, T. J., and French, G. L. 2000. Rapid diagnosis of bacteremia by universal amplification of $23 \mathrm{~S}$ ribosomal DNA followed by hybridization to oligonucleotide array. J. Clin. Microbiol. 38:781-788.

Antoniacci, L., Bugiani, R., Rossi, R., Calzolari, A., Alessandrini, A., Gozzi, R., Spinelli, F., Donati, I., Buriani, G., Mauri, S. 2015. Validation of the New Zealand Psa forecasting model in Emilia Romagna Region (Italy). Abstract. Page 41 in: Second International Psa Symposium, Bologna, Italy.

Balestra, G. M., Mazzaglia, A., Quattrucci, A., Renzi, M., and Rossetti, A. 2009. Current status of bacterial canker spread on kiwifruit in Italy. Australas. Plant Dis. Notes 4:34-36.

Balestra, G. M., Renzi, M., and Mazzaglia, A. 2010. First report of bacterial canker of Actinidia deliciosa caused by Pseudomonas syringae pv. actinidiae in Portugal. New Dis. Rep. 22:10.

Bastas, K. K., and Karakaya, A. 2012. First report of bacterial canker of kiwifruit caused by Pseudomonas syringae pv. actinidiae in Turkey. Plant Dis. 96:452.

Billing, E. 2008. Guidance on the use of Billing's integrated system (BIS) for fire blight risk assessment. Acta Hortic. 793:473-483.

Bulger, M. A., Ellis, M. A., and Madden, L. V. 1987. Influence of temperature and wetness duration on infection of strawberry flowers by Botrytis cinerea and disease incidence on fruit originating from infected flowers. Phytopathology 77:1225-1230.

Ciliberti, N., Fermaud, M., Languasco, L., and Rossi, V. 2015. Influence of fungal strain, temperature, and wetness duration on infection of grapevine inflorescences and young berry clusters by Botrytis cinerea. Phytopathology 105:325-33.

Duthie, J. A. 1997. Models of the response of foliar parasites to the combined effects of temperature and duration of wetness. Phytopathology 87: 1088-1095.

Everett, K. R., Taylor, R. K., Romberg, M. K., Rees-George, J., Fullerton, R. A., Vanneste, J. L., and Manning, M. A. 2011. First report of Pseudomonas syringae pv. actinidiae causing kiwifruit bacterial canker in New Zealand. Australas. Plant Dis. Notes 6:67-71.

Ferrante, P., and Scortichini, M. 2014. Frost promotes the pathogenicity of Pseudomonas syringae pv. actinidiae in Actinidia chinensis and A. deliciosa plants. Plant Pathol. 63:12-19.

Ficke, A., Gadoury, D. M., and Seem, R. C. 2002. Ontogenic resistance and plant disease management: A case study of grape powdery mildew. Phytopathology 92:671-675.

Froud, K. J., Everett, K. R., Tyson, J. L., Beresford, R. M., and Cogger, N. 2015. Review of the risk factors associated with kiwifruit bacterial canker caused by Pseudomonas syringae pv. actinidiae. N. Z. Plant Prot. 68: 313-327.

Gullino, M. L., Gilardi, G., Sanna, M., and Garibaldi, A. 2009. Epidemiology of Pseudomonas syringae pv. syringae on tomato. Phytoparasitica 37: 461-466.

Hirano, S. S., and Upper, C. D. 2000. Bacteria in the leaf ecosystem with emphasis on Pseudomonas syringae-A pathogen, ice nucleus, and epiphyte. Microbiol. Mol. Biol. Rev. 64:624-653.

Hughes, G. 2012. Applications of information theory to epidemiology. The American Phytopathol. Soc., St Paul, Minnesota., 151 pp.

Hughes, G., McRoberts, N., and Burnett, F. J. 2015. Information graphs for binary predictors. Phytopathology 105:9-17.
King, E. O., Ward, M. K., and Raney, D. E. 1954. Two simple media for the demonstration of pyocyanin and fluorescin. J. Lab. Clin. Med. 44:301-307.

Koh, Y. J., Cha, B. J., Chung, H. J., and Lee, D. H. 1994. Outbreak and spread of bacterial canker in kiwifruit. Korean J. Plant Pathol. 10:68-72.

Latorre, B. A., Lillo, C., and Rioja, M. E. 2002. Effects of temperature, free moisture duration and inoculum concentration on infection of sweet cherry by Pseudomonas syringae pv. syringae. Phytoparasitica 30:410-419.

Li, Y., Cheng, H., Fang, S., and Qian, Z. 2001. Preliminary forecast of kiwifruit bacterial canker infection caused by Pseudomonas syringae pv. actinidiae. Chin. J. Appl. Ecol. 12:355-358.

Lightner, G. W., and Steiner, P. W. 1993. An update on version 4.1 of the MARYBLYT computer program for predicting fire blight. Acta Hortic. 338: 131-136.

MacHardy, W. E., and Gadoury, D. M. 1989. A revision of Mills's criteria for predicting apple scab infection periods. Phytopathology 79:304-310.

Magarey, R. D., Sutton, T. B., and Thayer, C. L. 2005. A simple generic infection model for foliar fungal plant pathogens. Phytopathology 95: 92-100.

McRoberts, N., Hall, C., Madden, L. V., and Hughes, G. 2011. Perceptions of disease risk: From social construction of subjective judgments to rational decision making. Phytopathology 101:654-665.

Mohan, S. K., and Schaad, N. W. 1987. An improved agar plating assay for detecting Pseudomonas syringae pv. syringae and $P$. s. pv. phaseolicola in contaminated bean seed. Phytopathology 77:1390-1395.

Pyke, N. B., Stanley, C. J., and Warrington, I. J. 1986. Kiwifruit: Frost tolerance of plants in controlled frost conditions. N. Z. J. Exp. Agr. 14: 443-447.

Rees-George, J., Vanneste, J. L., Cornish, D. A., Pushparajah, I. P. S., Yu, J., Templeton, M. D., and Everett, K. R. 2010. Detection of Pseudomonas syringae pv. actinidiae using polymerase chain reaction (PCR) primers based on the 16S-23S rDNA intertranscribed spacer region and comparison with PCR primers based on other gene regions. Plant Pathol. 59:453-464.

Rouse, D. I., Nordheim, E. V., Hirano, S. S., and Upper, C. D. 1985. A model for relating the probability of foliar disease incidence to the population frequencies of bacterial plant pathogens. Phytopathology 75:505-509.

Scherm, H., and van Bruggen, A. H. C. 1993. Response surface models for germination and infection of Bremia lactucae, the fungus causing downy mildew of lettuce. Ecol. Modell. 65:281-296.

Scortichini, M. 1994. Occurrence of Pseudomonas syringae pv. actinidiae on kiwifruit in Italy. Plant Pathol. 43:1035-1038.

Serizawa, S., and Ichikawa, T. 1993. Epidemiology of bacterial canker of kiwifruit 4. Optimum temperature for disease development on new canes. Ann. Phytopathol. Soc. Jpn. 59:694-701.

Smith, T. J. 1999. Report on the development and use of Cougarblight $98 \mathrm{C}-\mathrm{A}$ situation-specific fire blight risk assessment model for apple and pear. Acta Hortic. 489:429-436.

Sobiczewski, P., and Jones, A. L. 1992. Effect of exposure to freezing temperatures on necrosis in sweet cherry shoots inoculated with Pseudomonas syringae pv. syringae or P. s. morsprunorum. Plant Dis. 76:447-451.

Takikawa, Y., Serizawa, S., Ichikawa, T., Tsuyumu, S., and Goto, M. 1989. Pseudomonas syringae pv. actinidiae pv. nov.: The causal bacterium of canker of kiwifruit in Japan. Ann. Phytopathol. Soc. Jpn. 55:437-444.

Tyson, J. L., Horner, I. J., Curtis, C. L., Blackmore, A., and Manning, M. A. 2015. Influence of leaf age on infection of Actinidia species by Pseudomonas syringae pv. actinidiae. N. Z. Plant Prot. 68:328-331.

Tyson, J. L., Rees-George, J., Curtis, C. L., Manning, M. A., and Fullerton, R. A. 2012. Survival of Pseudomonas syringae pv. actinidiae on the orchard floor over winter. N. Z. Plant Prot. 65:25-28.

Vanneste, J. L. 2013. Recent progress on detecting, understanding and controlling Pseudomonas syringae pv. actinidiae: A short review. N. Z. Plant Prot. 66:170-177.

Vanneste, J. L., Poliakoff, F., Audusseau, C., Cornish, D. A., Paillard, S., Rivoal, C., and Yu, J. 2011. First report of Pseudomonas syringae pv. actinidiae, the causal agent of bacterial canker of kiwifruit in France. Plant Dis. 95:1311.

Vanneste, J. L., Yu, J., Cornish, D. A., Tanner, D. J., Windner, R., Chapman, J. R., Taylor, R. K., Mackay, J. F., and Dowlut, S. 2013. Identification, virulence, and distribution of two biovars of Pseudomonas syringae pv. actinidiae in New Zealand. Plant Dis. 97:708-719.

Wang, Z., Tang, X., and Liu, S. 1992. Identification of the pathogenic bacterium for bacterial canker on Actinidia in Sichuan. Joural of Southwest Agricultural University, Tsinghua Tongfang Knowledge Network Technology Co., Ltd. Beijing. http://en.cnki.com.cn/Article_en/CJFDTOTAL-XNND199206007.htm Youden, W. J. 1950. Index for rating diagnostic tests. Cancer 3:32-35.

Zehr, E. I., Shepard, D. P., and Bridges, W. C. 1996. Bacterial spot of peach as influenced by water congestion and temperature. Plant Dis. 80: $339-341$. 